\title{
Article \\ Integrated and Portable Probe Based on Functional Plastic Scintillator for Detection of Radioactive Cesium
}

\author{
Sujung Min ${ }^{1,2}$, Hara Kang ${ }^{1}$, Bumkyung Seo ${ }^{1}$, Changhyun Roh ${ }^{1,3, * \mathbb{C}}$, Sangbum Hong ${ }^{1, *}$ and Jaehak Cheong ${ }^{2, *} \mathbb{C}$ \\ 1 Decommissioning Technology Research Division, Korea Atomic Energy Research Institute, \\ Daejeon 34057, Korea; sjmin@kaeri.re.kr (S.M.); mqovopm@kaeri.ac.kr (H.K.); bumja@kaeri.re.kr (B.S.) \\ 2 Department of Nuclear Engineering, Kyung-Hee University, Yongin-si 17104, Gyeonggi-do, Korea \\ 3 Quantum Energy Chemical Engineering, University of Science and Technology (UST), 217 Gajeong-ro, \\ Daejeon 34113, Korea \\ * Correspondence: chroh@kaeri.re.kr (C.R.); sbhong@kaeri.re.kr (S.H.); jhcheong@khu.ac.kr (J.C.)
}

Citation: Min, S.; Kang, H.; Seo, B.; Roh, C.; Hong, S.; Cheong, J.

Integrated and Portable Probe Based on Functional Plastic Scintillator for Detection of Radioactive Cesium. Appl. Sci. 2021, 11, 5210. https:// doi.org/10.3390/app11115210

Academic Editor: Antonio

Di Bartolomeo

Received: 10 May 2021

Accepted: 2 June 2021

Published: 4 June 2021

Publisher's Note: MDPI stays neutral with regard to jurisdictional claims in published maps and institutional affiliations.

Copyright: (c) 2021 by the authors. Licensee MDPI, Basel, Switzerland. This article is an open access article distributed under the terms and conditions of the Creative Commons Attribution (CC BY) license (https:// creativecommons.org/licenses/by/ $4.0 /)$.

\begin{abstract}
The highly reliable and direct detection of radioactive cesium has gained potential interest due to in-situ detection and monitoring in environments. In this study, we elucidated an integrated and portable probe based on functional plastic scintillator for detection of radioactive cesium. A functional plastic scintillator with improved detection efficiency was fabricated including CdTe (cadmium telluride) material. Monolith-typed functional plastic scintillator having a diameter of $50 \mathrm{~mm}$ and a thickness of $30 \mathrm{~mm}$ was manufactured by adding 2,5-diphenyloxazole (PPO, $0.4 \mathrm{wt} \%$ ), 1,4 di[2-(5phenyloxazolyl)]benzene (POPOP, $0.01 \mathrm{wt} \%)$, and CdTe $(0.2 \mathrm{wt} \%)$ materials in a styrene-based matrix. To evaluate the applicability of the plastic scintillator manufactured to in-situ radiological measurement, an integrated plastic detection system was created, and the measurement experiment was performed using the Cs-137 radiation source. Additionally, detection efficiency was compared with a commercial plastic scintillator. As results, the efficiency and light yield of a functional plastic scintillator including CdTe were higher than a commercial plastic scintillator. Furthermore, the remarkable performance of the functional plastic scintillator was confirmed through comparative analysis with Monte Carlo simulation.
\end{abstract}

Keywords: detection; integrated portable probe; Cs-137; plastic scintillator; simulation

\section{Introduction}

In general, it is necessary to develop residual radioactivity measurement technology that can easily access the site, and the technology in radiological measurements that can safely and effectively evaluate the environment, contaminated by a nuclear safeguard or serious accident at a nuclear facility [1-7]. In addition, there must be verified that the site is not contaminated for reuse of the site after the nuclear facilities are dismantled. Until now, a lot of studies have been conducted to secure technologies that can prepare for serious accidents such as Chernobyl and Fukushima [7-13]. The total amount of radioactivity emitted by the Chernobyl accident was about $12 \times 10^{18} \mathrm{~Bq}$ [14]. The behavior of radioactive particles largely depends on diffusion factor, particle size, and rainfall, and large particles such as nuclear fuel dust were mostly deposited within $100 \mathrm{~km}$ radius of the reactor [13]. In the Chernobyl nuclear accident, radioactive Cs-137 from one of the fission products of U-235 contaminated about 125,000 $\mathrm{km}^{2}$ in Belarus, Ukraine, and Western Russia with a concentration of $37 \mathrm{kBq} / \mathrm{m}^{2}$ [13]. In the Fukushima accident, a large area was contaminated by the radioactive elements, and one of the major contaminated radionuclides was analyzed as a Cs-137 [12,13]. Additionally, Cs-137 was easily released from the nuclear power plant accident and was rapidly spread to the environments as a mobile element. The decay diagram and probability of Cs-137 were shown in Figure 1 and Table 1 . Most of Cs-137 decays to Ba-137 and then gamma decays to a stable state at $0.662 \mathrm{MeV}$. There are two $\beta^{-}$decay channels. First, $94.6 \%$ of $\beta^{-}$decays proceed from Cs-137 to the excited state 
of Ba- $137 \mathrm{~m}$ with maximum electron energy of $0.514 \mathrm{MeV}$. The Ba- $137 \mathrm{~m}$ is a metastable state that decays with a 2.552 min half-life to the ground state of Ba-137 with emission of a $0.662 \mathrm{MeV}$ gamma ray photon. Second, $5.4 \%$ of $\beta^{-}$decay proceeds directly from Cs-137 to the ground state of Ba-137 with maximum electron energy of $1.176 \mathrm{MeV}$. Cs-137 has a half-life of $30.17 \pm 0.03$ years [15], which can cause long-term damage when exposed to the environment [16-25]. Cesium has similar chemical properties to potassium (K), so it is easily concentrated in crops such as rice. In addition, it occupies a large amount of artificial radioactive gamma-emitting isotopes that have been leaked through nuclear tests and nuclear accidents. In this regard, cesium is an important radionuclide for detection and monitoring in environments and contaminated sites.

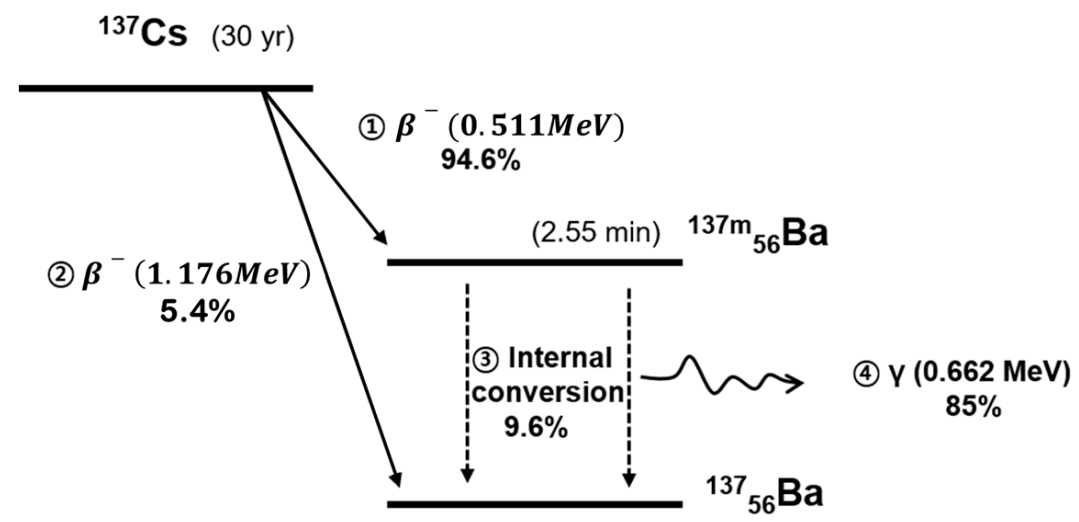

Figure 1. Decay of diagram of ${ }^{137} \mathrm{Cs}$.

Table 1. $\beta^{-}$decay process, electron energy, and probability of Cs-137.

\begin{tabular}{|c|c|c|c|c|c|}
\hline & ${ }^{137} \mathrm{Cs}$ & $\left(E_{k}\right)_{\max }$ & $\left(E_{k}\right)_{\text {avg }}$ & $\left(\mathrm{E}_{\gamma}\right)$ & Probability \\
\hline (1) & $\beta^{-}$decay & $0.514 \mathrm{MeV}$ & $0.170 \mathrm{MeV}$ & - & $94.6 \%$ \\
\hline (2) & $\beta^{-}$decay & $1.176 \mathrm{MeV}$ & $0.420 \mathrm{MeV}$ & - & $5.4 \%$ \\
\hline \multirow[t]{2}{*}{ (3) } & $\begin{array}{l}\text { Internal conversion } \\
\text { (K shell) }\end{array}$ & - & - & - & $7.8 \%$ \\
\hline & $\begin{array}{c}\text { Internal conversion } \\
(\mathrm{L}, \mathrm{M} \text { shell })\end{array}$ & - & - & - & $1.80 \%$ \\
\hline (4) & $\gamma$ decay & - & - & $0.662 \mathrm{MeV}$ & $85 \%$ \\
\hline
\end{tabular}

Plastic detectors are widely used as large size detectors. Additionally, over the past few decades, many studies have been conducted on plastic scintillators composed of polymer matrix containing nanomaterials as an alternative to conventional inorganic scintillators [26]. Plastic scintillators are generally manufactured by thermal polymerization, doping, or coating by adding materials such as fluorescent dye. However, direct mixing of nanomaterials and polymers is less efficient in producing transparent nanocomposites. Because nanomaterials tend to aggregate due to their high specific surface area and surface energy, transparency is lost by Rayleigh scattering. To increase the transparency, research is required to reduce the aggregation of nanomaterials [27]. The plastic detector is composed of a low atomic number material such as $\mathrm{C}, \mathrm{H}, \mathrm{O}$, so its accuracy is low due to low stopping power and light yield. Because of these properties, plastic scintillators are used in applications such as fast neutron detection, charged particle tracking, and non-destructive testing. Plastic scintillators have advantages over inorganic scintillators such as faster decay time (about $10 \mathrm{~ns}$ ), non-hygroscopicity, relatively low manufacturing cost, robustness, and processability. Using these advantages, it is possible to develop a plastic scintillator with improved detection efficiency by adding nanomaterials of high atomic number to the plastic matrix [28-36].

In general, Monte Carlo codes are widely used for radiation instrument design, performance evaluation of prototypes, and detector calibration [37-40]. The performance 
of the commercial plastic and the CdTe-loaded plastic scintillator was verified through the MCNP simulation. MCNP is a relatively accurate evaluation method for solving a three-dimensional transport equation. In the Monte Carlo method, the spatial structure is simulated exactly as the actual structure and the reaction cross-sectional area is used as a continuous function of energy.

In this study, we elucidated an integrated and portable probe based on a functional plastic scintillator for detection of radioactive cesium. In addition, the results were compared and analyzed with the results of the MCNP simulation.

\section{Materials and Methods}

\subsection{Chemicals}

All chemicals and reagents were commercial products. Styrene $(99.9 \%), 2,5-$ Diphenyloxazole (PPO, >95\%), 1,4-bis(5-phenyloxazol-2-yl) benzene (POPOP, $>95 \%$ ), and CdTe used were purchased from Sigma-Aldrich (St. Louis, MO, USA) on a technical purity grade.

\subsection{Fabrication of a Functional Plastic Scintillator}

A styrene-based plastic scintillator was fabricated by a polymerization method, and its performance was compared and analyzed with a PVT-based commercial scintillator (EJ-200). Plastics were manufactured by the process shown in Figure 2. The materials used in the manufacture of plastics were styrene, PPO (2,5-diphenyloxazole), POPOP (1,4 di[2(5phenyloxazolyl)]benzene), CdTe, and plastics with a diameter of $50 \mathrm{~mm}$ and a thickness of $30 \mathrm{~mm}$. Styrene was used as the primary solvent, PPO was used as the primary fluorophore, and POPOP was used as the secondary fluorophore. Although the types of nanomaterials are various, CdTe was used. The contents ( $\mathrm{wt} \%$ ) of organic dye and CdTe were selected due to previous studies [31]. The amounts of materials added to the styrene were PPO $(0.4 \mathrm{wt} \%)$, POPOP $(0.01 \mathrm{wt} \%)$, and nanomaterials $(0.2 \mathrm{wt} \%)$. The plastic scintillator used styrene as a basic matrix material, and a nanomaterial having an emission wavelength range of 500-600 nm was selected. CdTe nanomaterial was mixed with the matrix material, and stirred at $60{ }^{\circ} \mathrm{C}$. After the stirring process for about $2-3 \mathrm{~h}$ was completed, the weight suitable for the thickness of the plastic was measured. The sample was placed in a vial for polymerization and fine bubbles generated during stirring were removed. Fine bubbles can cause cracking due to internal stress during the polymerization process, and since it reduces optical properties. Bubble removal process of about $1-2 \mathrm{~h}$ is required. The de-bubbled sample is polymerized in a vacuum oven at a temperature of up to $120^{\circ} \mathrm{C}$. At this time, it is important to increase the temperature slowly, and if the temperature is increased rapidly, bubbles in the sample may be regenerated. The polymerization process takes about $70 \mathrm{~h}$. Plastics that have gone through the polymerization process are finished after cutting and polishing the surface to increase the transmittance.

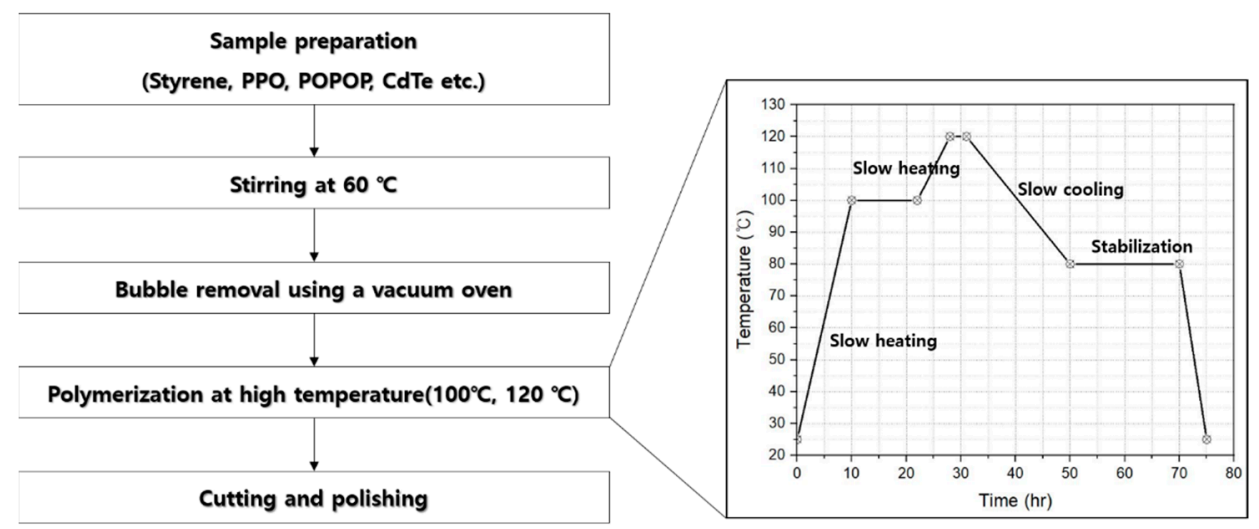

Figure 2. Manufacturing process of a functional plastic scintillator. 


\subsection{MCNP Simulation}

Monte Carlo simulation is a method for solving problems of physical and mathematical systems by generating random numbers and using a probabilistic model. The MCNP code can construct various geometry through the cell card. After modeling the actual geometry through the MCNP computational simulation, the spectrum of the energy accumulated in the scintillator was obtained. And, input data of surface flux in a MCNP 6 simulation was presented in Figure S1.

Figure 3 is the result of calculating the deposited energy for each thickness using MCNP to select the plastic scintillator thickness. The energy of the incident photon is deposited through interaction as it passes through the scintillator. Figure 3a shows the geometry for computational simulation, and the Cs-137 radiation source was placed $20 \mathrm{~mm}$ away from the plastic surface. Figure $3 b$ shows the flux by thickness, and Figure $3 c$ shows the energy spectrum by thickness. In this study, a plastic scintillator was fabricated with a thickness of $30 \mathrm{~mm}$ showing about $70 \%$ energy deposition.

(a)

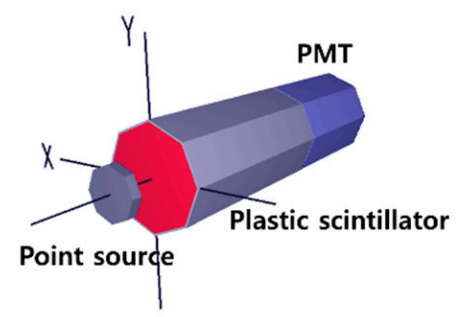

(b)
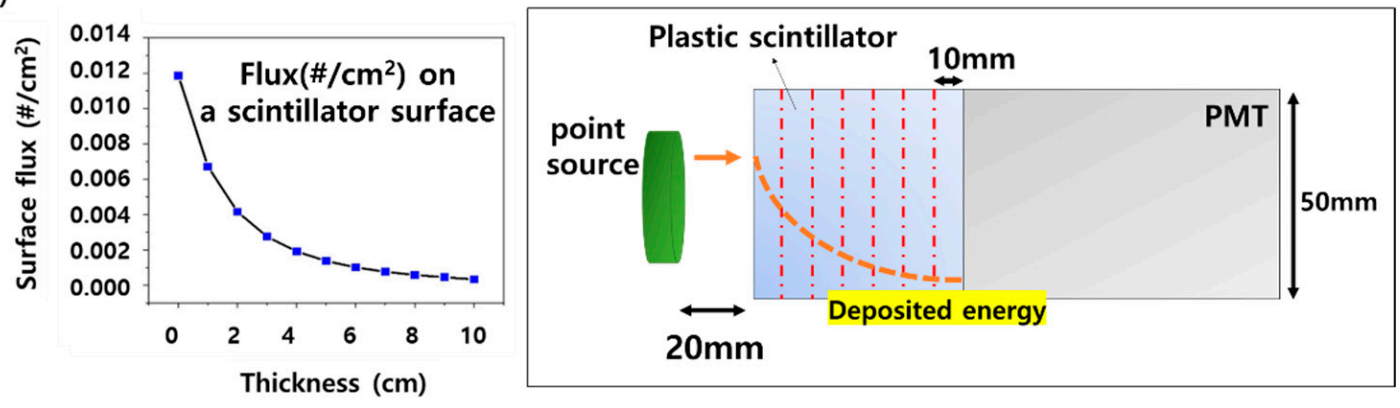

(c)

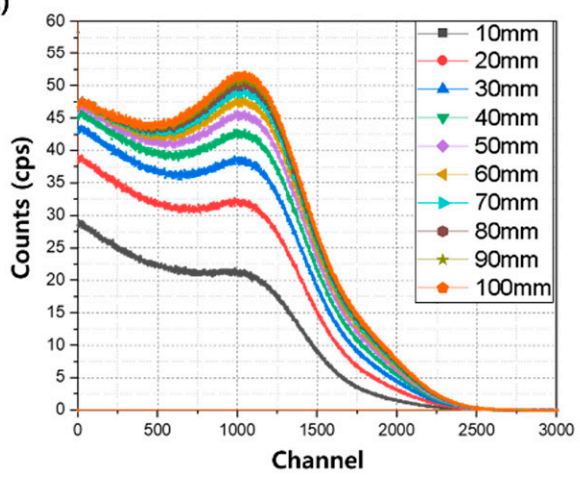

Figure 3. The geometry used in the MCNP computational simulation for the selection of plastic thickness (a), flux by thickness (left), configuration of geometry (right) (b), energy spectrum by thickness (c).

Figure 4 shows the geometry for computational simulation of a plastic detector manufactured with a selected $30 \mathrm{~mm}$ thickness. The distance of the radiation source was set to $20 \mathrm{~mm}, 50 \mathrm{~mm}$, and $100 \mathrm{~mm}$ under the same conditions as the experiment, and the gamma energy emitted from the radiation source was set to emit only a single energy of interest. Here, only one detector and one source are simulated, and the surrounding environment is 
not considered because it was not expected to have a significant impact on scattering. The size of the radiation source is $2.5 \mathrm{~cm}$ in diameter and the location of the source was used as a point in the simulation.
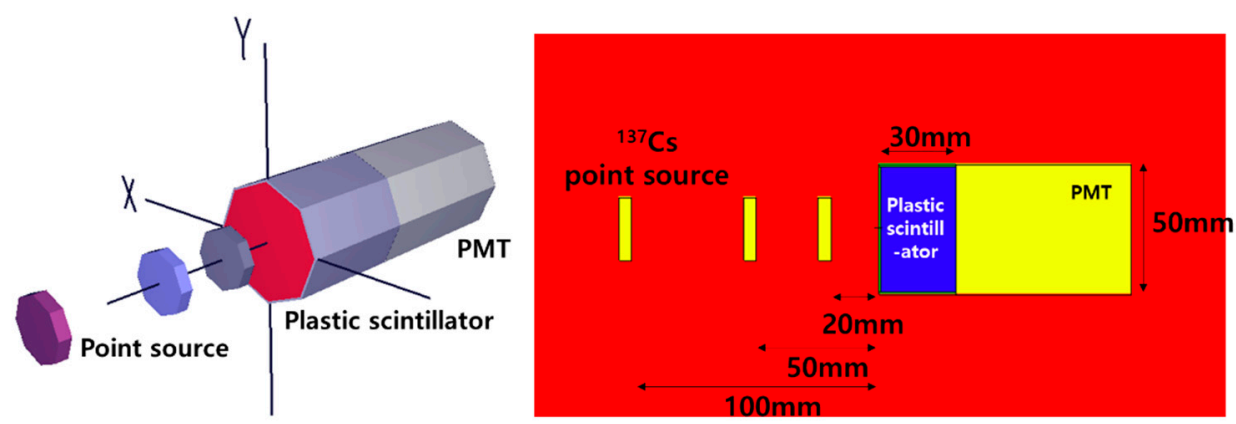

Figure 4. Geometry for computational simulation of 30-mm-thick plastic scintillators.

It was also set up using a Gaussian energy broadening (GEB) card to obtain the ideal Compton spectrum of the plastic scintillator. As the parameters for GEB in Equation (1), values of a, b, and c were applied as $0.00093789,0.00498$, and -0.05999 , respectively. And, all input data of energy spectrum were presented in Figure S2.

$$
\mathrm{FWHM}=\mathrm{a}+\mathrm{b} \sqrt{ }\left(\mathrm{E}+\mathrm{c} \mathrm{E}^{2}\right)
$$

Here, FWHM means full width at half maximum, E means gamma-ray energy.

The spectrum derived through the MCNP simulation was compared with the actual measurement spectrum, and since the photopeak did not appear due to the characteristics of the plastic scintillator, the detection efficiency was calculated using the gross counts. To make the statistical uncertainty of the calculation result less than $5 \%, 10^{9}$ photons were generated in each geometry to calculate the measurement efficiency of the plastic detector.

\subsection{Manufacturing of Integrated Functional Plastic Detection System}

To evaluate the performance of the CdTe-loaded plastic detector, a plastic detection system was constructed as shown in Figure 5a. Additionally, the signal generated from the plastic detector is amplified through a preamplifier and amplifier, and the amplified analog signal is digitized through a multi-channel analyzer and then stored. A high voltage was applied to the plastic detector so that the generated electrons were collected by the electrode. The system was constructed using PMT (ET-9266KB, ET-Enterprises Ltd., Uxbridge, UK), power supply (DT5423, CAEN, Viareggio, Italy), Preamp (Amcrys 544, Amcrys Ltd., Kharkiv, Ukraine), Amp (DT5781, CAEN, Viareggio, Italy), and MCA (DT5781, CAEN, Viareggio, Italy). Additionally, the plastic detector and data processing system were manufactured as an integrated system, so that the integrated system can be used as a portable detection system as shown in Figure 5b. Figure 5c shows a schematic illustration for plastic detection system. The integrated box can contain a data processing system, which is custom-made using an anti-shock sponge. Additionally, it was stored in a dark room for about $12 \mathrm{~h}$ after replacing the scintillator to remove the afterglow of the PMT that occurred while replacing the plastic scintillator. 
(a)

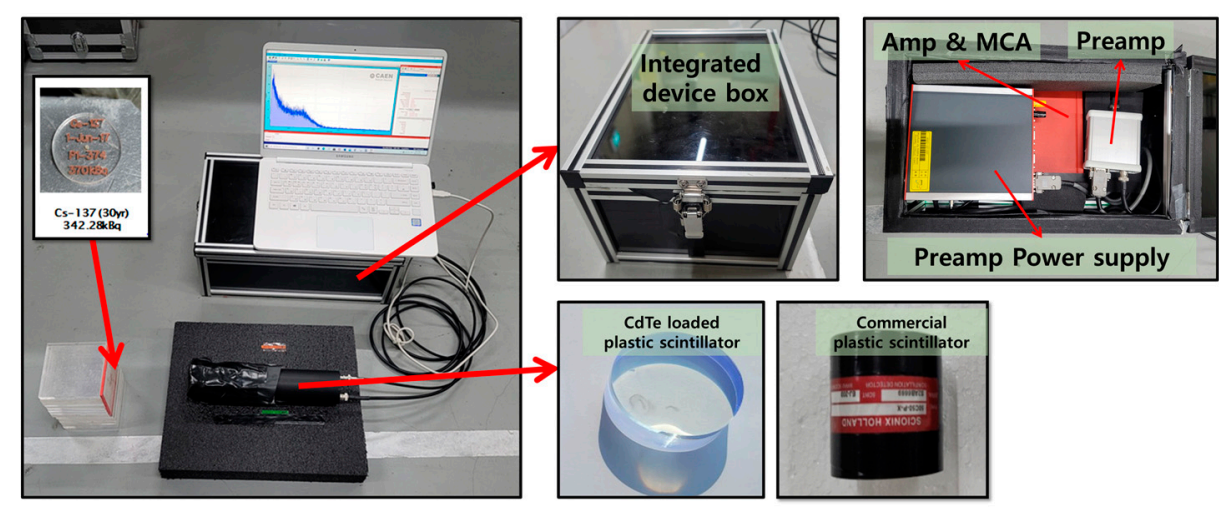

(b)

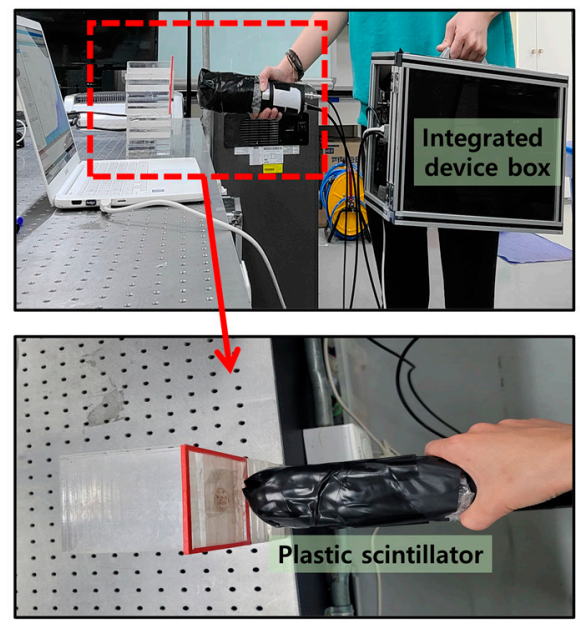

(c)

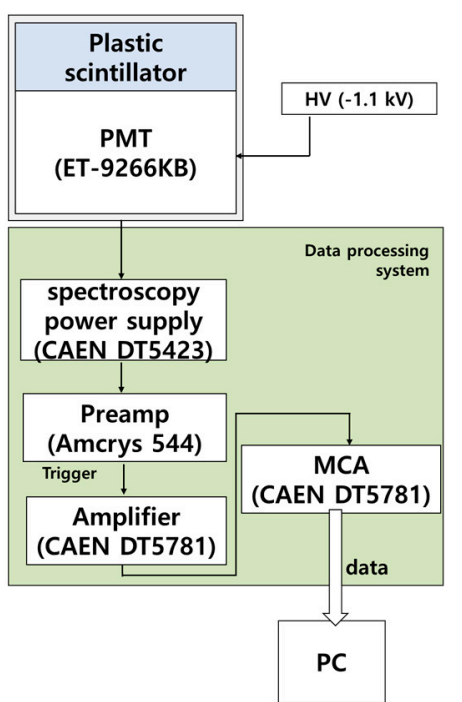

Figure 5. (a) Real picture of the performance experimental setup for gamma energy spectrum using a functional plastic scintillator. (b) Real picture of integrated device box and portable probe with a functional scintillator. (c) Schematic illustration for plastic detection system.

\section{Results and Discussion}

The transparency of the plastic scintillator decreases due to the coagulation of nanomaterials with high surface energy and precipitation during the plastic polymerization process, which may adversely affect the optical properties. Therefore, for the transparency of the plastic scintillator, it is necessary to be careful in the processes of stirring, bubbles removal, slow heating, slow cooling, and polishing. Figure 6a shows the transparency of the CdTe-loaded plastic, and Figure $6 \mathrm{~b}, \mathrm{c}$ show the UV-Vis absorption and PL emission spectra of the plastic scintillator. The absorption peak was confirmed at about 250-400 nm, and $475 \mathrm{~nm}$ emission was observed under $316 \mathrm{~nm}$ excitation.

As mentioned in the introduction, incident photons tend to deposit all the energy on the photoelectrons generated by interacting with $\mathrm{CdTe}$, a nanomaterial of high atomic number, through the photoelectric effect. This energy goes through an energy cascade process, where the plastic matrix and dye are excited to generate excitons. Energy transfer characteristics are maximized through fluorescent dyes. Typically, through the FRET pro-cess, energy is transferred between molecules. As the nanomaterials were loaded, the emission wavelength shifted through the FRET process and the emission intensity increased. This means that compared to conventional fluorescent dyes, quantum efficiency is increased due to nanomaterials, and thus greater fluorescence is generated. 
(a)

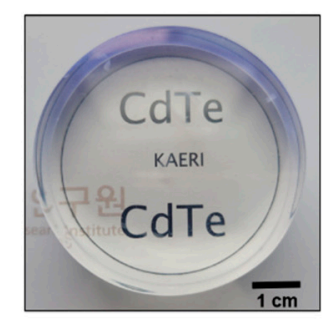

(b)

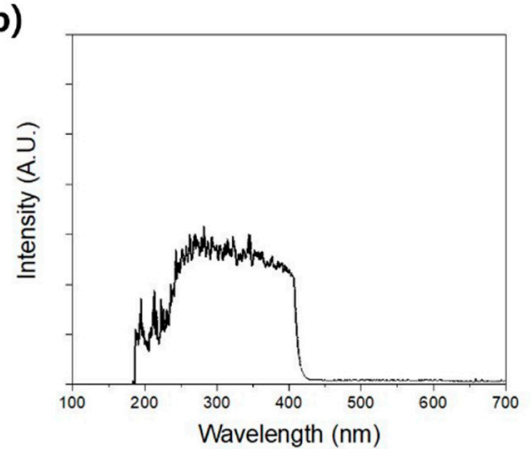

(c)

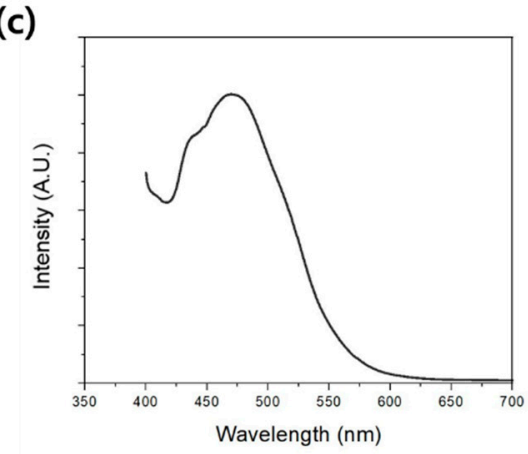

Figure 6. (a) A functional plastic scintillator including CdTe. (b) UV-Vis absorbance. (c) Photoluminescence emission spectrum, excitation at $316 \mathrm{~nm}$.

To compare the performance of a plastic scintillator produced by adding CdTe material with a commercial scintillator, a measurement test was performed by placing a source at a distance of $20 \mathrm{~mm}$ from the scintillator surface. Considering the half-life, the radioactivity of the Cs-137 source is $342.28 \mathrm{kBq}$. Unlike inorganic scintillators, plastic scintillators rarely generate photoelectric effects, and Compton scattering mainly occurs. Compton edge energies of Cs- 137 used in this experiment are $477.3 \mathrm{keV}$. Since the plastic scintillator is dominated by Compton scattering, energy calibration was performed using the Compton edge and measurement tests were performed for $10 \mathrm{~min}$. The results of the measurement test using a point source for each plastic scintillator are shown in Figure 6. Additionally, the result of calculating the output by gross count of the measured spectrum is shown in the Table 2. The relative efficiency of the CdTe-loaded plastic scintillator was calculated using Equation (2) as the gross counting method for the commercial plastic scintillator, and as a result, it was confirmed that it increased by $25 \%$ compared to the commercial plastic scintillator. However, the measurement result using the point source analyzed that the Compton edge of commercial plastics has better resolution. This is because of the transmission loss due to Rayleigh scattering, and aggregation of a solid form CdTe nanomaterials.

Table 2. Compared relative efficiency for detection of radioactive cesium.

\begin{tabular}{ccccc}
\hline & & $\begin{array}{c}\text { Net Count } \\
\text { (cps) }\end{array}$ & $\begin{array}{c}\text { Relative } \\
\text { Efficiency } \\
\mathbf{( \% )}\end{array}$ & $\begin{array}{c}\text { Detection } \\
\text { Efficiency } \\
\mathbf{( \% )}\end{array}$ \\
\hline Commercial & $20 \mathrm{~mm}$ & $3,644,431 \pm 495,634$ & 100.00 & 2.09 \\
plastic & $50 \mathrm{~mm}$ & $1,332,009 \pm 99,208$ & 100.00 & 0.76 \\
& $100 \mathrm{~mm}$ & $474,203 \pm 23,352$ & 100.00 & 0.27 \\
\hline \multirow{2}{*}{ Plastic without } & $20 \mathrm{~mm}$ & $1,803,557 \pm 2657$ & 49.49 & 1.03 \\
CdTe & $50 \mathrm{~mm}$ & $781,528 \pm 582$ & 58.67 & 0.45 \\
& $100 \mathrm{~mm}$ & $303,323 \pm 53$ & 63.96 & 0.17 \\
Plastic with & $20 \mathrm{~mm}$ & $4,100,748 \pm 558,312$ & 112.52 & 2.35 \\
CdTe & $50 \mathrm{~mm}$ & $1,608,902 \pm 120,952$ & 120.79 & 0.92 \\
& $100 \mathrm{~mm}$ & $593,654 \pm 331$ & 125.19 & 0.34 \\
\hline
\end{tabular}


In addition, the detection efficiency of commercial plastics and the CdTe plastic scintillator was measured. The detection efficiency was calculated using Equation (3). In Table 2, the gross count rate increased as the CdTe nanomaterial was added. This means that the high atomic number of $\mathrm{CdTe}$ increases the reaction rate with photons, thereby improving the efficiency.

$$
\text { Relative efficiency }(\%)=\frac{\text { Total counts }(\text { CdTe loaded plastic })}{\text { Total counts }(\text { Commercial plastic })} \times 100
$$

$$
\text { Detection efficiency }(\%)=\frac{\text { Net counts }(\mathrm{cps})}{\text { Radioactivity }(\mathrm{Bq}) \times \operatorname{Release} \text { Probability }(\%)} \times 100
$$

Figure 7 shows the spectrum measured by radiation source distance for commercial plastics, plastics loaded with CdTe, and plastics not loaded with CdTe. The spectrum in Figure 7 shows the net count minus the background radiation, and is a graph normalized to $477.65 \mathrm{keV}$, the Compton edge energy of Cs-137. Spectral data were obtained by dividing the energy of $3 \mathrm{MeV}$ by a total of 8192 channels. It was confirmed that as the distance of the radiation source increased, the number of counts decreased.

(a)

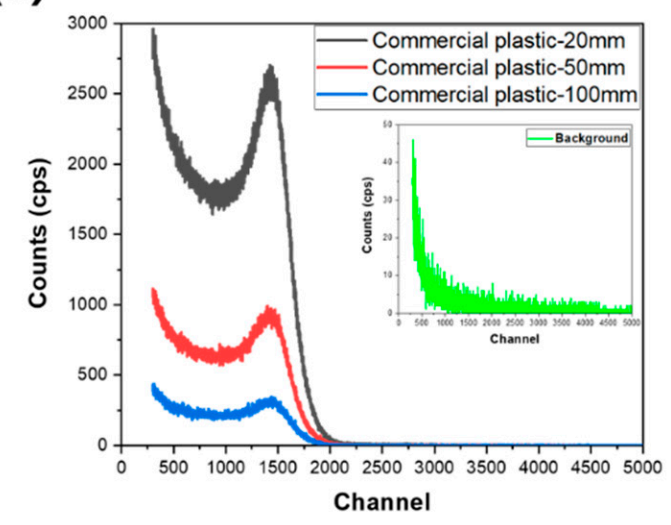

(b)

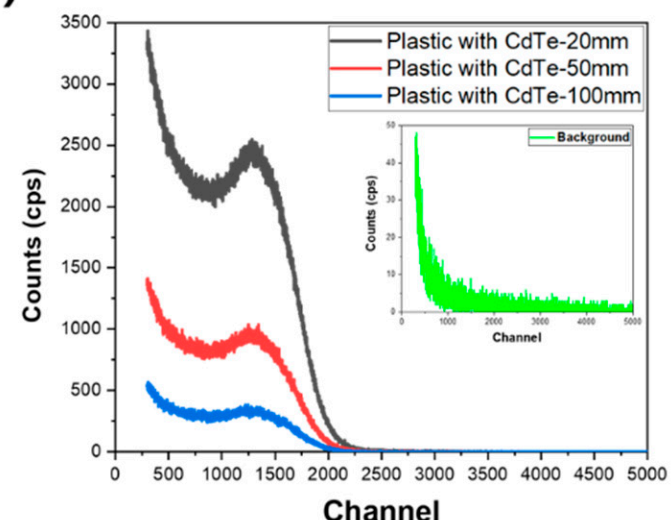

(c)

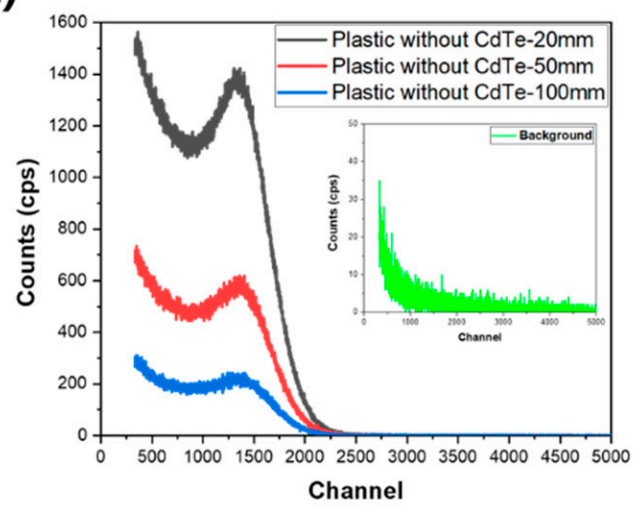

Figure 7. Normalized energy spectrum by distance. (a) Commercial plastic scintillator. (b) Plastic scintillator with CdTe. (c) Plastic scintillator without CdTe.

Figure 8 represents the measurement data for three plastic scintillators, and it means the average value of the measured data by distance. As shown in Figure 8, it was observed that in the case of the scintillator to which the nanomaterial was added, the Compton peak was shifted to the left compared to the commercial scintillator. Based on this, the light yield 
for the CdTe scintillator was calculated using the light yield of EJ-200. Light yield was calculated based on the data in Figure 8 and Equation (4) [41].

$$
\mathrm{LY}_{\mathrm{Cd}}=\mathrm{LY}_{\mathrm{EJ}} \times \frac{\mathrm{CE}_{\mathrm{Cd}}}{\mathrm{CE}} \times \frac{\mathrm{QE}_{\mathrm{EJ}}}{\mathrm{QE}_{\mathrm{Cd}}}
$$

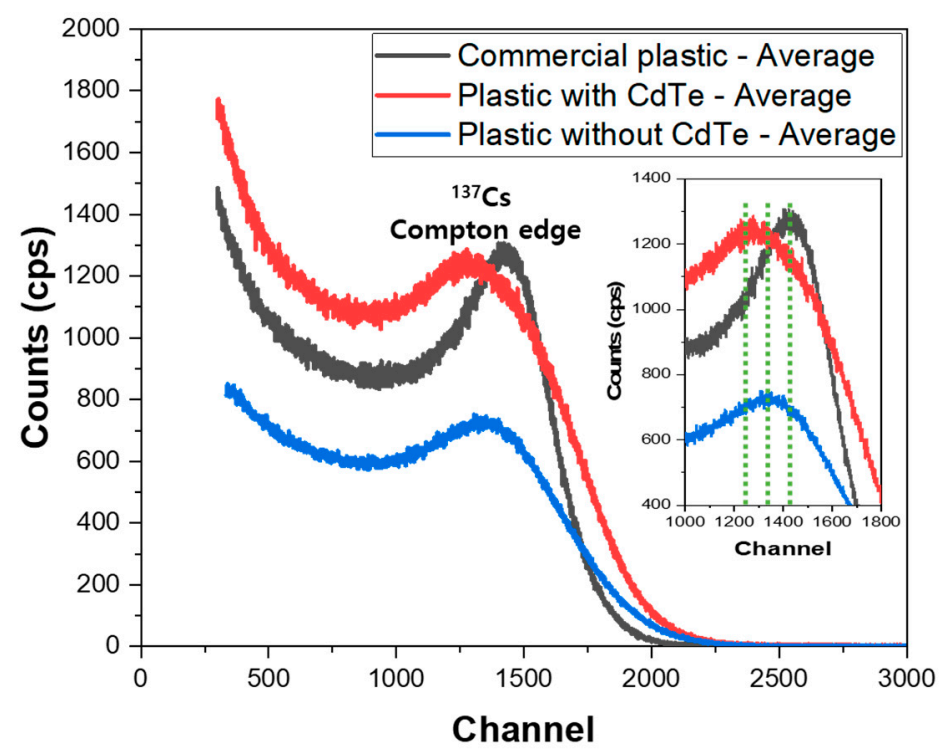

Figure 8. Gamma measurement spectrum of three plastic scintillators using Cs-137 point source. Insert figure represents relative counts from channel 1000 to 1800.

Here, LY, CE, and QE refer to the light yield, the peak channel of Compton's edge, and the quantum efficiency of PMT at the emission wavelength, respectively, and EJ and Cd refer to the commercial scintillator and the plastic scintillator loaded with CdTe, respectively. As shown in Table 3, the $\mathrm{LY}_{\mathrm{EJ}}$ value was used as a reference value of 10,000 photon/MeV, a value suggested by Eljen technology. In addition, $\mathrm{QE}$ used the values in the datasheet of PMT (ET-9266KB) [42]. When CdTe was loaded, it was confirmed that the light yield increased compared to commercial plastic scintillator. Based on this result, it is analyzed that the CdTe nanomaterial not only increases the reaction rate with photons, but also improves the energy transfer rate.

Table 3. Compared relative light yield by distance to Cs-137 gamma ray source.

\begin{tabular}{cccc}
\hline Terms & $\mathbf{2 0 ~} \mathbf{~ m m}$ & $\mathbf{5 0 ~} \mathbf{~ m}$ & $\mathbf{1 0 0} \mathbf{~ m m}$ \\
\hline $\mathrm{CE}_{\mathrm{Cd}}$ & $1295 \mathrm{ch}$ & $1298 \mathrm{ch}$ & $1291 \mathrm{ch}$ \\
$\mathrm{CE}$ & $1430 \mathrm{ch}$ & $1444 \mathrm{ch}$ & $1434 \mathrm{ch}$ \\
$\mathrm{QE}_{\mathrm{Cd}}$ & & $0.15 \%$ & \\
$\mathrm{QE}_{\mathrm{EJ}}$ & & $0.2 \%$ & \\
$\mathrm{LY}$ & & 10,000 photon $/ \mathrm{MeV}$ & \\
Relative $\mathrm{LY}$ & & 12,103 photon $/ \mathrm{MeV}$ & 12,037 photon $/ \mathrm{MeV}$ \\
\hline
\end{tabular}

Figure 9 shows the result of comparing the spectrum of commercial plastic scintillator (EJ-200) and CdTe-loaded plastic scintillator with MCNP simulation. The average relative error in the Compton edge region was analyzed to be within 5\%. In the MCNP simulation results of Figure $7 \mathrm{~b}$, a signal was detected in a region larger than the Compton edge by CdTe with a high atomic number. The reason that these signals are not seen in the experimental results is likely due to the aggregation due to the low solubility and high surface energy of CdTe. In order to analyze the influence of CdTe nanomaterials, the count ratio was calculated through the Equation (5). As a result, it showed a high coefficient ratio 
at the Compton edge energy of Cs-137. In addition, a ratio above ' 1 ' means that the CdTe nanomaterial improved the light yield in the polymer corresponding to each channel. In this study, according to the Figure 10, it is shown that there is an improvement of more than $10 \%$ by CdTe nanomaterials. The count rate was greatly improved in the $477 \mathrm{keV}$ Compton energy region by CdTe nanomaterials. In addition, the results analyzed below ' 1 ' indicate that the effect of nanomaterials may be the effect of light loss and signal overlap due to aggregation of nanomaterials.

$$
\text { Count ratio }=\frac{\text { count rate per channel }[\mathrm{PS}(\mathrm{PPO}, \mathrm{POPOP})-\mathrm{CdTe}]}{\text { Count rate per channel }[\mathrm{PS}(\mathrm{PPO}, \mathrm{POPOP})]}
$$

(a)

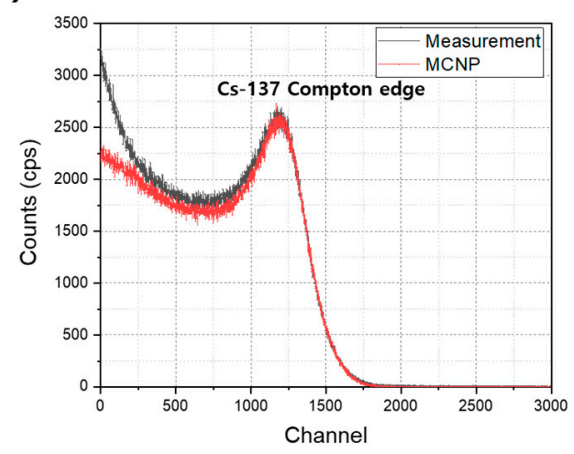

(b)

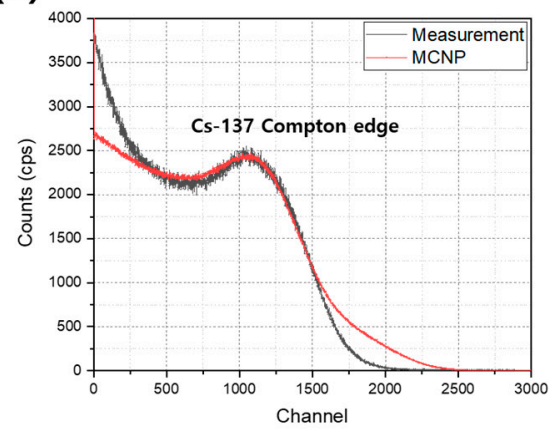

Figure 9. Normalized results from measured and simulated energy spectrum of commercial and CdTe-loaded plastic scintillator to Cs-137 gamma ray source. (a) Point source measurement using commercial plastic scintillator. (b) Point source measurement using a functional plastic scintillator including CdTe.

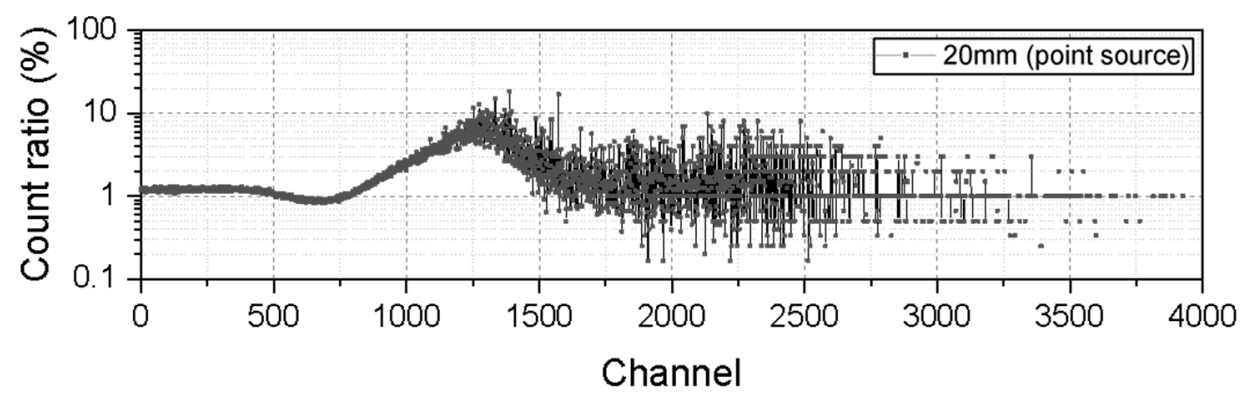

Figure 10. Count ratio from gamma spectra from a functional plastic scintillator.

CdTe nanoparticles have advantages such as the change of energy gap according to the size of nanomaterials, light emission due to the discontinuity in energy state density, increase in light efficiency, and light emission (even at room temperature) due to the increase in the binding energy of excitons. Until now, there have been a great deal of studies for use in CdTe nanoparticles, like optical materials, as shown in Table 4, and important studies are being conducted to improve the energy transfer rate by doping inorganic particles into CdTe nanoparticles. 
Table 4. Progress of CdTe-enabled optical materials.

\begin{tabular}{|c|c|c|c|c|}
\hline Nanomaterials & Methods & Results & Year & Ref. \\
\hline $\begin{array}{l}\mathrm{CdTe} / \mathrm{BaFBr}: \mathrm{Eu}^{2+} \\
\text { nanocomposite } \\
\text { phosphors }\end{array}$ & $\begin{array}{l}\text { - CdTe QD is weak in X-ray emission, so } \\
\text { a CdTe/BaFBr:Eu }{ }^{2+} \text { nanocomposite was } \\
\text { prepared to evaluate its property. } \\
\text { - Analyze the size and structure of } \\
\text { nanoparticles by TEM. }\end{array}$ & $\begin{array}{l}\text { - Strength increases as energy is } \\
\text { transferred from } \mathrm{Eu}^{2+} \text { to CdTe QD. } \\
\text { - As it can be emitted in the near } \\
\text { infrared range ( } 650-1100 \mathrm{~nm}) \text {, which is a } \\
\text { tissue optical window for in vivo } \\
\text { imaging, the possibility of using it as a } \\
\text { semiconductor/phosphor } \\
\text { nanocomposite material is evaluated. }\end{array}$ & 2006 & [43] \\
\hline
\end{tabular}

- After synthesis by adding CdTe QD

having various emission ranges to

PMMA-based materials, the

CdTe quantum dots applicability to the $\mathrm{X}$-ray imaging field

and polymer was evaluated.

nanocomposites

- A nanocomposite film containing

$0.1-10 \mathrm{wt} \%$ of CdTe QD was prepared and the characteristics were evaluated.

- Use of bulk polymerization method to secure transparency

Excellent $\mathrm{X}$-ray emission results including high resolution, fast decay time, afterglow prevention, high

stopping power, and excellent spectral matching to the CCD detector

- $\mathrm{LaF}_{3}: \mathrm{Ce} / \mathrm{CdTe}$ nanocomposite was prepared to observe the $\mathrm{X}$-ray emission characteristics of CdTe QD

- Analyze the size and structure of nanoparticles through TEM
- The X-ray emission of CdTe QD is very weak, but the emission of

$\mathrm{LaF}_{3}: \mathrm{Ce} / \mathrm{CdTe}$ increases (six times)

- CdTe QD shows the characteristics of

intense photoluminescence and up-conversion light emission, and short decay time characteristics

- CdTe is widely used due to the simplicity of the structure and the efficiency compared to the doped amount, and the efficiency of the $\mathrm{CdTe}$-based solar cell is improved through the $\mathrm{CdCl}_{2}$ heat treatment

Devices

- In order to improve the performance of the CdTe-based solar cell, the developed $\mathrm{CdCl}_{2}$ heat treatment was applied to the $\mathrm{CdTe}$ of the upper layer structure in which most of the reactions occur. - Improved efficiency by controlling the junction of CdTe-based solar cells method.

- By improving the characteristics of the interface layer (IFL), it shows an efficiency of $10.97 \%$.
- A facile one-step synthesis of CdTe quantum dots (QDs) in aqueous solution by atmospheric microwave reactor has been developed using 3-mercaptopropionic acid reduction of $\mathrm{TeO}_{2}$ directly.

- The obtained CdTe QDs were characterized by ultraviolet-visible spectroscopy, fluorescent spectroscopy, X-ray powder diffraction, multifunctional imaging electron spectrometer (XPS), and high-resolution transmission electron microscopy

- A plastic detector is manufactured by adding a fluorescent material and a

Plastic scintillator containing $\mathrm{Gd}_{2} \mathrm{O}_{3}$ or CdTe nano material $\left(\mathrm{Gd}_{2} \mathrm{O}_{3}\right.$ or CdTe) to an epoxy-based material.

- Evaluating the efficiency using a beta source (Sr-90)
- Green to red-emitting CdTe QDs with

a maximum photoluminescence quantum yield of $56.68 \%$ were obtained. - The as-synthesized CdTe QDs were highly luminescent, which ensures their

promising future applications as biological labels
- As a result of characterization evaluation after adding the concentration of QD by $0.05-1 \mathrm{wt} \%$, optimized concentration. 
Table 4. Cont.

\begin{tabular}{|c|c|c|c|c|}
\hline Nanomaterials & Methods & Results & Year & Ref. \\
\hline $\begin{array}{l}\text { Silver ion-doped CdTe } \\
\text { quantum dots }\end{array}$ & $\begin{array}{l}\text { - This is a study to use CdTe QD as a } \\
\text { fluorescent probe for } \mathrm{Hg}^{2+} \text { detection } \\
\text { - To expand the detection concentration } \\
\text { range of } \mathrm{Hg}^{2+}, \mathrm{Ag} \text { ions were doped with } \\
\text { CdTe QD } \\
\text { - The characteristics of the produced QD } \\
\text { were analyzed. }\end{array}$ & $\begin{array}{l}\text { - As a result of investigating the release } \\
\text { mechanism of Ag-doped CdTe QD, it } \\
\text { shows multiple release in QD samples } \\
\text { with high } \mathrm{Ag}^{+} \text {doping concentration } \\
\text { - The highest PL quantum yield of the } \\
\text { QD sample was analyzed as } 59.4 \%\end{array}$ & 2020 & [48] \\
\hline
\end{tabular}

- Develop CdTe QD synthesis method to improve quantum yield

- Evaluating the characteristics of specific substances (SAL) by

Thioglycolic concentration through fluorescence acid-capped CdTe quantum dots quenching mechanism - Using the ratio of ([Cd2+]:[HTe-]:[TGA(Thioglycolic acid)] $=1: 0.5: 2.4), \mathrm{CdTe} \mathrm{QD}$ with high photoluminescence was synthesized at $140{ }^{\circ} \mathrm{C}$.

- Synthesizing CdTe with an emission wavelength of 540-560 nm and evaluating the possibility of using it for SAL detection

- Evaluating the concentration of additives (SAL) using the degree of extinction of QD
- Using CdTe coated with $\mathrm{SiO}_{2}$ $\left(\mathrm{CdTe} @ \mathrm{SiO}_{2}\right)$ and PMMA, a

Non-polar PMMA quantum dots by silica coating solvent of CdTe nanocomposite material was produced that efficiently exhibits Stokes shift - The characteristics of CdTe coated with silica and without silica were compared and analyzed.
- In the PMMA/CdTe thin film without silica coating, non-uniform CdTe particles act as defects in the matrix. - In the PMMA/CdTe thin film coated with silica, clusters of uniform size were observed.

- The emission spectrum of $\mathrm{SiO}_{2}$ overlaps with the excitation wavelength range of $\mathrm{CdTe} \mathrm{QD}$ to increase the response of the optical system

- The optical properties of CdTe QD

- Comparison of optical and structural characteristics between CdTe QDs - Analyzing the optical properties of $\mathrm{CdTe}$ nanocrystals made with various synthesis parameters

CdTe quantum dots using a binary solvent (water and glycerin)

- A study on the spectral characteristics of a wide range of CdTe quantum dots and wide-gap graphene QD was conducted.

CdTe quantum dots and graphene quantum dots

- A technology to replace the organic shell of CdTe QD of various sizes was proposed.

- Light stability when irradiated with radiation on CdTe QD and wide-gap graphene quantum dots was compared and analyzed.

- Monolith-typed functional plastic scintillator having a diameter of $50 \mathrm{~mm}$ and a thickness of $30 \mathrm{~mm}$ was

CdTe/PPO/POPOP/ manufactured by adding

Polystyrene

2,5-diphenyloxazole (PPO, $0.4 \mathrm{wt} \%$ ), 1,4

di[2-(5phenyloxazolyl)]benzene

(POPOP, $0.01 w t \%)$, and CdTe (0.2 wt\%)

materials in a styrene-based matrix. showed the highest emission quantum yield when synthesized with a binary solvent.

- CdTe QD prepared with a Cd:Te molar

ratio of 20:1 showed a narrow

photoluminescence band and improved quantum yield

- Colloidal graphene quantum dots and

$\mathrm{CdTe}$ investigated in this work retain their optical and structural properties when exposed to radiation in the visible range

- In the case of CdTe QD, the maximum

intensity of the irradiated sample did not change within the measurement error, but in the case of graphene QD, the intensity decreased when irradiated with ultraviolet rays.

- Integrated and portable probe based on a functional plastic scintillator for detection of Cs-137.

- Remarkable performance of the

This functional plastic scintillator was work confirmed through comparative analysis with Monte Carlo simulation. 


\section{Conclusions}

In this study, we elucidated an integrated and portable probe based on functional plastic scintillator for detection of radioactive cesium. The performance of the CdTe-loaded plastic scintillator was compared with a commercial plastic scintillator. The performance of the CdTe-loaded plastic scintillator was analyzed using Cs-137 point source. After setting the distance between the radiation source and the detector to $20 \mathrm{~mm}$, the energy spectrum was analyzed, and the reliability of the result was secured by comparing with the MCNP simulation result. When the functional plastic scintillator equipped with CdTe was compared with the commercial plastic scintillator, the relative efficiency increased by up to $25 \%$, and the detection efficiency was also increased. In addition, as a result of calculating the relative light yield based on the light yield of the commercial plastic scintillator, it was confirmed that the light yield increased when CdTe was loaded. It is expected that a highefficiency and high-sensitivity plastic detection system can be developed by optimizing the amount of nanomaterials in the future and can be applied the measurement data processing methodology. Finally, the highly reliable and direct detection of radioactive cesium based on an integrated portable probe including a functional plastic scintillator will pave the way for potential interest due to in situ detection and monitoring in environmental sites for nuclear facilities and radiation measurements.

Supplementary Materials: The following are available online at https:/ /www.mdpi.com/article/ 10.3390/app11115210/s1. Figure S1: Input data of surface flux in a MCNP 6 simulation; Figure S2: Input data of energy spectrum in a MCNP 6 simulation.

Author Contributions: Conceptualization, and original draft preparation: S.M., H.K. and B.S.; supervision and editing C.R., S.H. and J.C. All authors have read and agreed to the published version of the manuscript.

Funding: This research received no external funding.

Institutional Review Board Statement: Not applicable.

Informed Consent Statement: Not applicable.

Data Availability Statement: Data available on request from the authors.

Acknowledgments: This work was supported by the Nuclear Research and Development Program through the National Research Foundation (NRF) of Korea funded by Ministry of Science and ICT (No. 2017M2A8A5015143).

Conflicts of Interest: The authors declare no conflict of interest.

\section{References}

1. Seo, B.K.; Kwon, S.W.; Nam, J.S.; Roh, C.H.; Moon, J.K.; Ahn, B.G.; Yang, H.M.; Lee, G.W.; Lee, I.H.; Jeong, K.H.; et al. Development of Decommissioning, Decontamination and Remediation Technology for Nuclear Facilities; No. KAERI/RR-3939/2015; Korea Atomic Energy Research Institute: Daejeon, Korea, 2015.

2. Yukiyasu, N.; Mami, Y.; Yukihisa, S.; Tatsuo, T. Distribution of the 134Cs/137Cs ratio around the Fukushima Daiichi nuclear power plant using an unmanned helicopter radiation monitoring system. J. Nucl. Sci. Technol. 2016, 53, 468-474.

3. Masamichi, C.; Hiroaki, T.; Haruyasu, N.; Genki, K.; Satoshi, M.; Tatsuo, T.; Kimiaki, S.; Yukiyasu, N. Utilization of 134Cs/137Cs in the environment to identify the reactor units that caused atmospheric releases during the Fukushima Daiichi accident. Sci. Rep. 2016, 6, 31376 .

4. Chino, M.; Nakayama, H.; Nagai, H.; Terada, H. Preliminary estimation of release amounts of 131I and 137Cs accidentally discharged from the Fukushima Daiichi nuclear power plant into atmosphere. J. Nucl. Sci. Technol. 2011, 48, 1129-1134. [CrossRef]

5. Kobayashi, T.; Nagai, H.; Chino, M.; Kawamura, H. Source term estimation of atmospheric release due to the Fukushima Dai-ichi Nuclear Power Plant accident by atmospheric and oceanic dispersion simulations. J. Nucl. Sci. Technol. 2013, 50, 255-264. [CrossRef]

6. Wai, K.M.; Krstic, D.; Nikezic, D.; Lin, T.H.; Yu, P.K.N. External Cesium-137 doses to humans from soil influenced by the Fukushima and Chernobyl nuclear power plants accidents: A comparative study. Sci. Rep. 2020, 10, 7902. [CrossRef] [PubMed]

7. Pollanen, R.; Toivonen, H.; Valkama, I. Transport of radioactive particles from the Chernobyl accident. Atmos. Environ. 1997, 31, 3575-3590. [CrossRef] 
8. Puhakka, T.; Jylha, K.; Saarikivi, P.; Koistinen, J.; Koivukoski, J. Meteorological factors influencing the radioactive deposition in Finland after the Chernobyl accident. J. Appl. Meteorol. Climatol. 1990, 29, 813-829. [CrossRef]

9. Krstić, D.; Nikezic, D.; Stevanovic, N.; Jelic, M. Vertical profile of 137Cs in soil. Appl. Radiat. Isot. 2004, 61, 1487-1492. [CrossRef]

10. Taira, Y.; Hayashida, N.; Tsuchiya, R.; Yamafuchi, H.; Takahashi, J.; Kazlovsky, A.; Urazalin, M.; Rakhypbekov, T.; Yamashita, S.; Takamura, N. Vertical distribution and estimated doses from artifcial radionuclides in soil samples around the Chernobyl Nuclear Power Plant and the Semipalatinsk Nuclear Testing Site. PLoS ONE 2013, 8, e57524. [CrossRef]

11. Ostlund, K.; Samuelsson, C.; Mattsson, S.; Raaf, C.L. The infuence of 134Cs on the 137Cs gamma-spectrometric peak-to-valley ratio and improvement of the peak-to-valley method by limiting the detector feld of view. Appl. Radiat. Isot. 2017, 128, 249-255. [CrossRef]

12. Yasunari, T.J.; Stohl, A.; Hayano, R.S.; Burkhart, J.F.; Eckhardt, S.; Yasunari, T. Cesium-137 deposition and contamination of Japanese soils due to the Fukushima nuclear accident. Proc. Natl. Acad. Sci. USA 2011, 108, 19530-19534. [CrossRef]

13. Guntay, S.; Powers, D.A.; Devell, L. The Chernobyl Reactor Accident Source Term: Development of a Consensus View; NEA/CSNI/R1995-24; Nuclear Energy Agency of the OECD(NEA): Issy-les-Moulineaux, France, 1996.

14. Claußen, A.; Rosen, A. 30 Years Living with Chernobyl, 5 Years Living with Fukushima. Health Effects of the Nuclear Disasters in Fukushima and Chernobyl; Beavis, M., Thomasson, C., Hiranuma, Y., Eds.; IPPNW Germany: Berlin, Germany, $2016 ;$ p. 17.

15. Radionuclide Half-Life Measurements Data. Available online: https:/ /www.nist.gov/pml/radionuclide-half-life-measurements / radionuclide-half-life-measurements-data (accessed on 1 June 2021).

16. Bikit, I.; Mrdja, D.; Veskovic, M.; Krmar, M.; Slivka, J.; Todorovic, N.; Bikit, K. Coincidence techniques in gamma-ray spectroscopy. J. Phys. Proc. 2012, 31, 84-92. [CrossRef]

17. Yunoki, A.; Kawada, Y.; Yamada, T.; Unno, Y.; Sato, Y.; Hino, Y. Absorption and backscatter of internal conversion electrons in the measurements of surface contamination of Cs-137. J. Appl. Radiat. Isot. 2013, 81, 261-267. [CrossRef] [PubMed]

18. Yoshizawa, Y. Beta and gamma ray spectroscopy of Cs-137. J. Nucl. Phys. 1958, 5, 122-140. [CrossRef]

19. Hsue, S.T.; Langer, L.M.; Tang, S.M. Precise determination of the shape of the twice forbidden beta spectrum of Cs-137. J. Nucl. Phys. 1966, 86, 47-55. [CrossRef]

20. Lavelle, K.B.; Essex, R.M.; Carney, K.P.; Cessna, J.T.; Hexel, C.R. A reference material for evaluation of 137 Cs radiochronometric measurements. J. Radioanal. Nucl. Chem. 2018, 318, 195-208. [CrossRef]

21. Cummings, D.G.; Sommers, J.D.; Adamic, M.L.; Jimenez, M.; Giglio, J.J.; Carney, K.P.; Grimm, K. Characterization of sealed radioactive sources: Uncertainty analysis to improve detection methods. J. Radioanal. Nucl. Chem. 2009, 282, 923-928. [CrossRef]

22. Merritt, J.S.; Taylor, J.G.V. Decay of Cesium137 Determined by Absolute Counting Methods. J. Anal. Chem. 1965, 37, 351-354. [CrossRef]

23. Behrens, H.; Christmas, P. The beta decay of 137Cs. J. Nucl. Phys. A 1983, 399, 131-140. [CrossRef]

24. Goodier, I.W.; Makepeace, J.L.; Stuart, L.E.H. The decay scheme of cesium 137. J. Appl. Radiat. Isot. 1975, 26, 490-492. [CrossRef]

25. Kulkarni, S.S.; Khadke, U.V. Low Energy Gamma Radiation Induced Effects on Ultrasonic Velocity and Acoustic Parameters in Polyvinylidene Fluoride Solution. J. Mat. 2016, 2016, 8470689. [CrossRef]

26. Gandini, M.; Villa, I.; Beretta, M.; Gotti, C.; Imran, M.; Carulli, F.; Fantuzzi, M.S.; Zaffalon, M.; Brofferio, C.; Manna, L.; et al. Efficient, fast and reabsorbtion free perovskite nanocrystal based sensitized plastic scintillators. Nat. Nanotechnol. 2020, 15, 462-468. [CrossRef]

27. Hajagos, T.J.; Liu, C.; Cherepy, N.J.; Pei, Q. High-Z Sensitized plastic scintillators: A review. Adv. Mater. 2018, $30,1706956$. [CrossRef] [PubMed]

28. Yoon, S.C.; Chang, S.Y.; Lee, T.Y.; Kim, B.H.; Jeong, D.Y.; Lee, S.Y.; Lee, K.C.; Lee, H.S.; Ha, C.W. A State of the Art on the Compton Suppression Technology for Background Reduction of the Gamma Spectrometry; No. KAERI/AR-1199/2018; Korea Atomic Energy Research Institute: Daejeon, Korea, 2018.

29. Letant, S.E.; Wang, T.F. Study of porous glass doped with quantum dots or laser dyes under alpha irradiation. Appl. Phys. 2006, 88, 103110. [CrossRef]

30. Dai, Q.; Li, D.; Chen, H.; Kan, S.; Li, H.; Gao, S.; Hou, Y.; Liu, B.; Zou, G. Colloidal CdSe nanocrystals synthesized in noncoordinating solvents with the addition of a secondary ligand: Exceptional growth kinetics. J. Phys. Chem. B 2006, 110, 16508-16513. [CrossRef]

31. Shafqat, U.L. Development of Element Loaded Plastic Scintillators. Master's Thesis, Department of Physics, Kyungpook National University, Daegu, Korea, July 2007.

32. Liu, C.; Hajagos, T.J.; Kishpaugh, D.; Jin, Y.; Hu, W.; Chem, Q.; Pei, Q. Facile Single-Precursor Synthesis and Surface Modification of Hafnium Oxide Nanoparticles for Nanocomposite $\gamma$-Ray Scintillators. Adv. Funct. Mater. 2015, 25, 4607-4616. [CrossRef]

33. Nam, J.S.; Kim, Y.E.; Hong, S.B.; Seo, B.K.; Kim, K.H. Performance Evaluation of a Plastic Scintillator for Making a In-situ Beta Detector. J. New Phys. Sae Mulli 2017, 67, 1080-1085. [CrossRef]

34. Sahi, S.; Magill, S.; Ma, L.; Xie, J.; Chen, W.; Jones, B.; Nygren, D. Wavelength-shifting properties of luminescence nanoparticles for high energy particle detection and specific physics process observation. Sci. Rep. 2018, 8, 10515. [CrossRef]

35. Oktyabrsky, S.; Yakimov, M.; Tokranov, V.; Murat, P. Integrated semiconductor quantum dot scintillation detector: Ultimate Limit for speed and light yield. IEEE Trans. Nucl. Sci. 2016, 63, 656-663. [CrossRef]

36. Nam, J.S.; Hong, S.B.; Seo, B.K.; Kim, Y.E. Characteristics of Beta-ray measurements of plastic scintillators containing $\mathrm{Gd}_{2} \mathrm{O}_{3}$ or CdTe. J. New Phys. Sae Mulli 2019, 69, 625-630. [CrossRef] 
37. Yalcin, S.; Gurler, O.; Gundogdu, O.; Kaynak, G. Monte Carlo simulation of gamma-ray total counting efficiency for a phoswich detector. Radiat. Meas. 2009, 44, 80-85. [CrossRef]

38. Han, B.S.; Shim, H.J.; Kim, C.H. Development and Valification of MCCARD Gamma-ray transport routine. In Proceedings of the Korean Nuclear Society Conference, Kyungju, Korea, 27-28 May 2004.

39. Park, J.W.; Yang, J.S.; Kim, H.J. A Study on Radiation Safety Measures for the Use of High-Energy Beta-Ray Sources in Medical Fields; No. KINS-HR-332; Korea Institute of Nuclear Safety: Daejeon, Korea, 2000.

40. Kim, G.H.; Park, J.W. Modeling of the plastic detector for measuring the in pipe beta-ray contamination using Monte Carlo simulation methods. In Proceedings of the Korean Radioactive Waste Society Conference, Jeju, Korea, 10-12 November 2004.

41. Zho, H.; Yu, H.; Redding, C.; Li, Z.; Chen, T.; Meng, Y.; Hajagos, T.J.; Hayward, J.P.; Pei, Q. Scintillation Liquids loaded with Hafnium Oxide Nanoparticles for spectral resolution of gamma rays. ACS Appl. Nano Mater. 2021, 4, 1220-1227. [CrossRef]

42. ET Enterprises. Available online: https://et-enterprises.com/products/photomultipliers/product/p9266b-series (accessed on 9 May 2021).

43. Chen, W.; Zhang, J.; Westcott, S.L. The origin of X-Ray luminescence from CdTe nanoparticles in CdTe/BaFBr:Eu ${ }^{2+}$ nanocomposite phosphors. J. Appl. Phys. 2006, 99, 34302. [CrossRef]

44. Kang, Z.; Zhang, Y.; Menkara, H.; Wagner, B.K.; Summers, C.J.; Lawrence, W.; Nagarkar, V. CdTe quantum dots and polymer nanocomposites for X-Ray scintillation and imaging. J. Appl. Phys. 2011, 98, 181914. [CrossRef] [PubMed]

45. Hossu, M.; Liu, Z.; Yao, M.; Ma, L.; Chen, W. X-ray luminescence of CdTe quantum dots in LaF F $_{3}$ Cd/CdTe nanocomposites. J. Appl. Phys. 2012, 100, 13109.

46. Dhere, R.G.; Duenow, J.N.; Dehart, C.M.; Li, J.V.; Kuciauskas, D.; Gessert, T.A. Development of Substrate Structure CdTe Photovoltaic Devices with Performance Exceeding 10\%. In Proceedings of the 2012 IEEE Photovoltaic Specialists Conference, Austin, TX, USA, 3-8 June 2012.

47. Shen, M.; Jia, W.; You, Y.; Hu, Y.; Li, F.; Tian, S.; Li, J.; Jin, Y.; Han, D. Luminescent properties of CdTe quantum dots synthesized using 3-mercaptopropionic acid reduction of tellurium dioxide directly. Nanoscale Res. Lett. 2013, 8, 253. [CrossRef]

48. Li, H.; Lu, W.; Zhao, G.; Song, B.; Zhou, J.; Dong, W.; Han, G. Silver ion-doped CdTe quantum dots as fluorescent probe for Hg ${ }^{2+}$ detection. RSC Adv. 2020, 10, 38965-38973. [CrossRef]

49. Zhang, J.; Wei, Y.; Qiu, S.; Xiong, Y. A highly selective and simple fluorescent probe for salbutamol detection based on thioglycolic acid-capped CdTe quantum dots. Spectrochim. Acta Part A Mol. Biomol. Spectrosc. 2021, 247, 119107. [CrossRef]

50. Flores-Pacheco, A.; Sanchez-Zeferino, R.; Saaveddra-Rodriguez, G. Enhanced Stokes-shift and dispersibility in non-polar PMMA solvent of CdTe quantum dots by silica coating. Chem. Phys. 2021, 544, 111102. [CrossRef]

51. Da Rosa, L.T.A.; Aversa, I.F.S.; Raphael, E.; Polo, A.S.; Duarte, A.; Schiavon, M.A.; Virtuoso, L.S. Improving Photoluminescence Quantum Yield of CdTe Quantum Dots Using a Binary Solvent (Water + Glycerin) in the One-Pot Approach Synthesis. J. Braz. Chem. Soc. 2021, 32, 860-868.

52. Goryunova, M.A.; Tsipotan, A.S.; Slabko, V.V. Photostability of CdTe Quantum Dots and Graphene Quantum Dots under their Continuous Visible and UV Irradiation. J. Sib. Fed. Univ. Math. Phys. 2021, 14, 249-257. 